\title{
FISIOLOGIA DA COAGULAÇÃO, ANTICOAGULAÇÃO E FIBRINÓLISE
}

\author{
OVERVIEW OF COAGULATION, ANTICOAGULATIONAND FIBRINOLYSIS
}

Rendrik F. Franco

Professor Livre-Docente de Hematologia e Hemoterapia. Coordenador do Serviço de Investigação em Hemofilia e Trombofilia, Fundação Hemocentro de Ribeirão Preto. Coordenador do Laboratório de Hemostasia, Hospital das Clínicas da Faculdade de Medicina de Ribeirão Preto, Universidade de São Paulo

CoRRESPondÊNCIA: FUNDHERP, Rua Tenente Catão Roxo, 2501 - 14051-140, Ribeirão Preto, SP. E-mail: rendri@hotmail.com

FRANCO RF. Fisiologia da coagulação, anticoagulação e fibrinólise. Medicina, Ribeirão Preto, 34: 229-237, jul./dez. 2001.

RESUMO: O presente artigo revisa aspectos de fisiologia dos sistemas de coagulação, anticoagulação e fibrinólise, que são relevantes para a compreensão de mecanimos etiopatogênicos operantes em doenças hemorrágicas e trombóticas.

UNITERMOS: Coagulação. Anticoagulação. Fibrinólise.

\section{INTRODUÇÃO}

A formação do coágulo de fibrina no sítio de lesão endotelial representa processo crítico para a manutenção da integridade vascular. Os mecanismos envolvidos nesse processo, constituintes do sistema hemostático, devem ser regulados para simultaneamente, contrapor-se à perda excessiva de sangue e evitar a formação de trombos intravasculares, decorrentes de formação excessiva de fibrina.

Os componentes do sistema hemostático incluem as plaquetas, os vasos, as proteínas da coagulação do sangue, os anticoagulantes naturais e o sistema de fibrinólise. O equilíbrio funcional dos diferentes "setores" da hemostasia é garantido por uma variedade de mecanismos, envolvendo interações entre proteínas, respostas celulares complexas, e regulação de fluxo sangüíneo. No presente capítulo, abordaremos os sistemas de coagulação e fibrinólise, responsáveis pela formação e dissolução do coágulo de fibrina, respectivamente. Adicionalmente, discussão acerca do papel de mecanismos reguladores desses dois sistemas será apresentada.

\section{COAGULAÇÃO}

A formação do coágulo de fibrina envolve complexas interações entre proteases plasmáticas e seus cofatores, que culminam na gênese da enzima trombina, que, por proteólise, converte o fibrinogênio solúvel em fibrina insolúvel. Progressos significativos ocorreram nas últimas décadas, concernentes à compreensão da fisiologia desse sistema e dos mecanismos que o regulam $^{(1,2)}$. Conforme assinalado a seguir, tais conhecimentos tiveram fundamental importância para a melhor compreensão da fisiologia da hemostasia e do papel das reações hemostáticas em doenças hemorrágicas e trombóticas.

Em 1964, Macfarlane e Davie \& Ratnoff propuseram a hipótese da "cascata" para explicar a fisiologia da coagulação do sangue ${ }^{(3,4)}$. Nesse modelo (Figura 1), a coagulação ocorre por meio de ativação proteolítica, sequiencial de zimógenos, por proteases do plasma, resultando na formação de trombina que, então, converte a molécula de fibrinogênio em fibrina. O esquema divide a coagulação em uma via extrínseca (envolvendo componentes do sangue, mas, tam- 
bém, elementos que usualmente não estão presentes no espaço intravascular) e uma via intrínseca (iniciada por componentes presentes no intravascular), que convergem no ponto de ativação do fator X ("via final comum”). Na via extrínseca, o fator VII plasmático (na presença do seu cofator, o fator tecidual ou tromboplastina) ativa diretamente o fator $\mathrm{X}$. Na via intrínseca, ativação do fator XII ocorre quando o sangue entra em contato com uma superfície, contendo cargas elétricas negativas (por exemplo, a parede de um tubo de vidro). Tal processo é denominado "ativação por contato" e requer ainda a presença de outros componentes do plasma: pré-calicreína (uma serinoprotease) e cininogênio de alto peso molecular (um cofator não enzimático). O fator XIIa ativa o fator XI, que, por sua vez, ativa o fator IX. O fator IXa, na presença de fator VIII, ativa o fator X da coagulação, desencadeando a geração de trombina e subseqüente formação de fibrina.

Não obstante haja a tradição de se dividir o sistema de coagulação do sangue em intrínseco e extrínseco, tal separação é atualmente entendida como inadequada do ponto de vista de fisiologia da coagulação, tendo em vista que a divisão não ocorre in vivo. Adicionalmente, alterações conceituais ocorreram desde a descrição do modelo da cascata no que diz respeito à importância relativa das duas vias de ativação da coagulação. Por exemplo, a julgar pela gravidade das manifestações hemorrágicas, decorrentes das deficiências dos "fatores intrínsecos" VIII e IX (Hemofilia A e B, respectivamente), postulou-se, no passado, que a via intrínseca teria maior relevância na fisiologia da coagulação. Essa idéia todavia não é correta: sabe-se que a deficiência de fator XI é associada a distúrbio hemorrágico leve, e deficiências dos fatores da ativação por contato (fator XII, précalicreína, cininogênio de alto peso molecular) não resultam em quadro hemorrágico. Os fatores intrínsecos, portanto, não têm importância primária na geração de fator IXa durante o processo hemostático normal, que sucede a injúria vascular. Por outro lado, a deficiência de fator VII (crucial para a "ativação ex-

\section{VIA INTRÍNSECA}
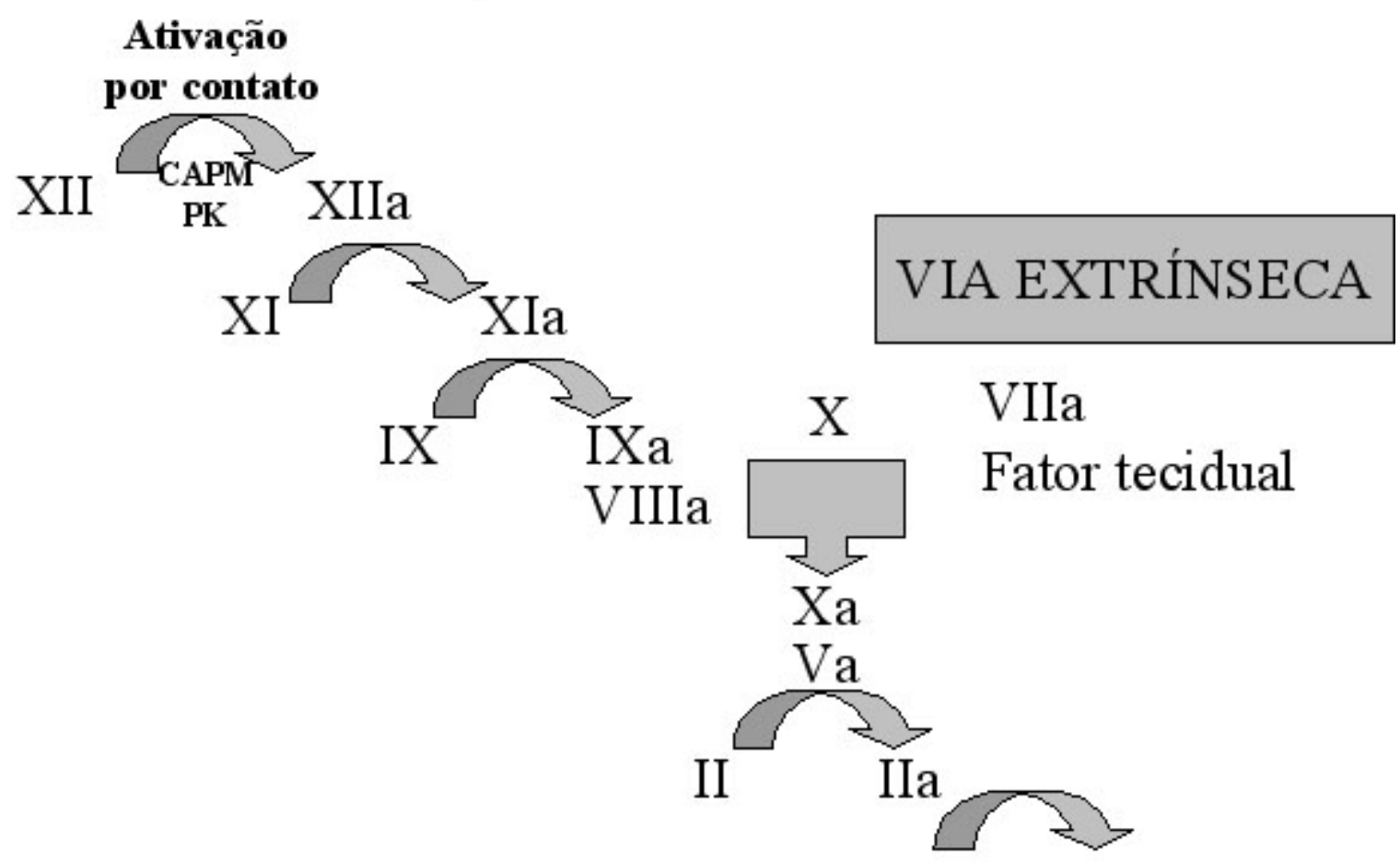

Fibrinogênio Fibrina

Figura 1. Esquema da cascata da coagulação, proposto na década de 1960, com a divisão do sistema de coagulação em duas vias. CAPM: cininogênio de alto peso molecular; PK: pré-calicreína. 
trínseca" da coagulação do sangue) é associada a quadro hemorrágico similar à Hemofilia. Em conjunto, esses dados demonstram que a ativação do fator IX não depende exclusivamente da via intrínseca e indicam que a coagulação do sangue é iniciada principalmente pela via do fator tecidual ou extrínseca. Adicionalmente, experimentos conduzidos nas últimas três décadas demonstraram que as vias intrínseca e extrínseca não exibem funcionamento independente, conforme detalhado a seguir.

Atualmente, aceita-se que mecanismos hemostáticos, fisiologicamente relevantes estejam associados com três complexos enzimáticos procoagulantes, os quais envolvem serinoproteases dependentes de vitamina $\mathrm{K}$ (fatores II, VII, IX e X) associadas a cofatores (V e VIII), todos localizados em uma superfície de membrana contendo fosfolipídeos ${ }^{(1,2)}$. Os complexos encontram-se esquematizados na Figura 2, que resume os dados apresentados a seguir.

As diversas enzimas da coagulação convertem seus substratos procofatores em cofatores, os quais localizam as proteases sobre as superfícies celulares, contendo fosfolipídeos (em especial das plaquetas), em que essas reações acontecem (Figura 2). Os elementos biológicos que contribuem para o componente de fosfolipídeos da coagulação incluem tecidos vasculares lesados, células inflamatórias e plaquetas ativadas. O principal contribuinte, em termos de números de sítios, são as membranas de plaquetas, que, quando ativadas, expressam sítios de ligação para os complexos fator IXa/fator VIIIa (complexo "tenase") e fator Xa/fator Va (complexo "protrombinase"). Adicionalmente, íons de cálcio são necessários em diversos passos das reações da coagulação.

A iniciação do processo de coagulação depende da exposição do sangue a componentes que, normalmente, não estão presentes no interior dos vasos, em decorrência de lesões estruturais (injúria vascular) ou alterações bioquímicas (por ex., liberação de citocinas). Qualquer que seja o evento desencadeante, a iniciação da coagulação do sangue se faz mediante expressão do seu componente crítico, o fator tecidual (FT), e sua exposição ao espaço intravascular.

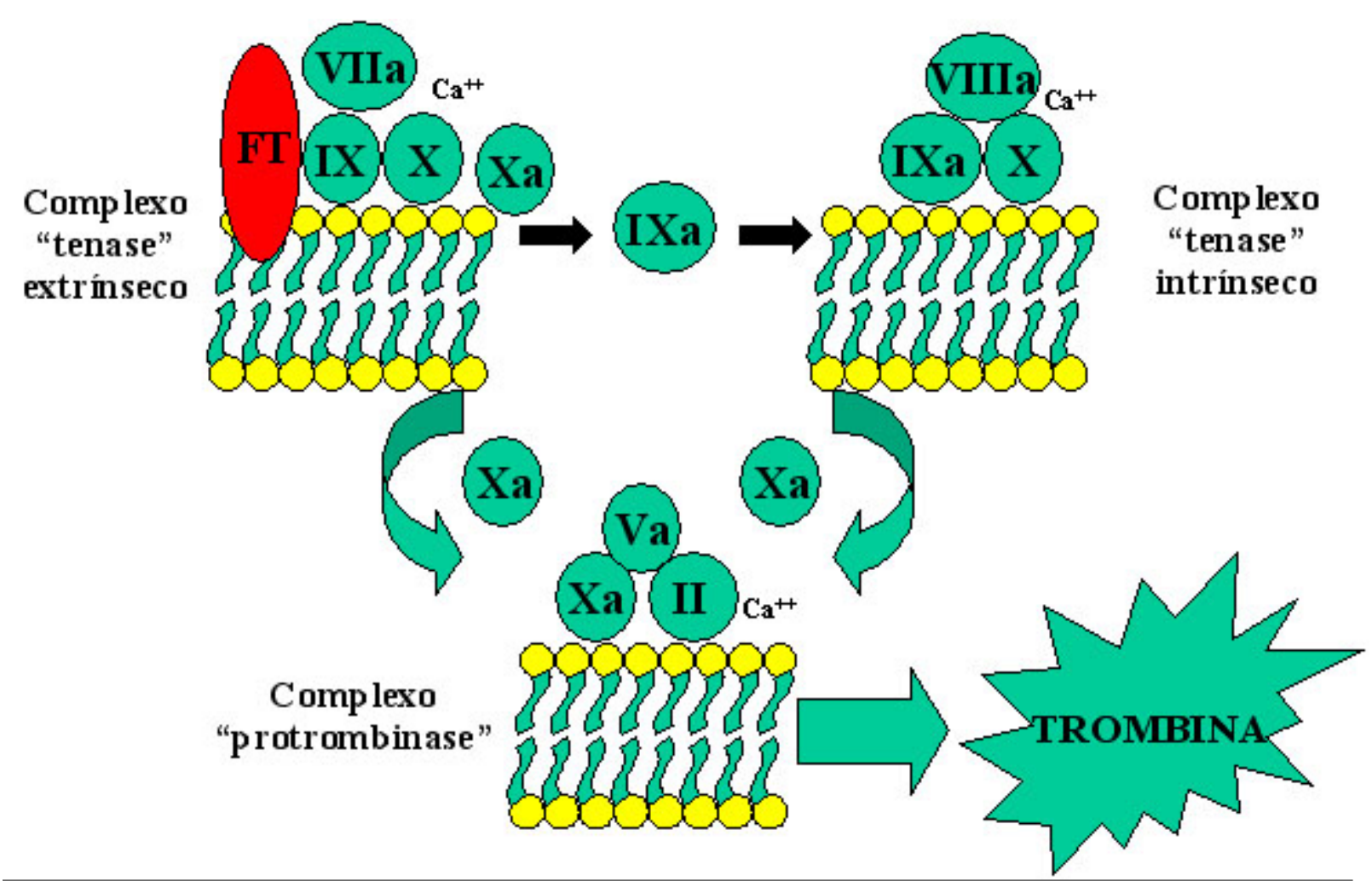

Figura 2: Representação esquemática dos complexos procoagulantes. O início da coagulação se faz mediante ligação do fator VIla ao fator tecidual (FT), com subseqüente ativação dos fatores IX e X. O complexo fator IXa/fator VIIla ativa o fator X com eficiência ainda maior, e o fator Xa forma complexo com o fator Va, convertendo o fator II (protrombina) em fator Ila (trombina). A superfície de membrana celular em que as reações ocorrem também encontra-se representada. Esquema adaptado da referência 1. 
O FT é uma glicoproteína de membrana de $45000 \mathrm{Da}$, que funciona como receptor para o fator VII da coagulação. O FT não é normalmente expresso em células em contato direto com o sangue (tais como células endoteliais e leucócitos) ${ }^{(5,6)}$, mas apresenta expressão constitutiva em fibroblastos subjacentes ao endotélio vascular ${ }^{(6)}$. O FT é também encontrado em queratinócitos, células epiteliais do trato respiratório e trato gastrointestinal, cérebro, células musculares cardíacas e glomérulos renais. Células endoteliais e monócitos, que, normalmente, não expressam o fator tecidual, podem expressá-lo na vigência de lesão endotelial e na presença de estímulos específicos, tais como endotoxinas e citocinas (TNF- $\alpha$ e interleucina-1 $)^{(7,8,9)}$. Em indivíduos normais, níveis mínimos da forma ativada do fator VII da coagulação (FVIIa) estão presentes em circulação, correspondendo a aproximadamente $1 \%$ da concentração plasmática total de fator VII. O FVIIa é capaz de se ligar ao FT expresso em membranas celulares, e a exposição do FT ao plasma resulta na sua ligação ao FVII e FVIIa, sendo que somente o complexo FT-FVIIa exibe função enzimática ativa; o complexo é também capaz de ativar o FVII em processo denominado "auto-ativação". O complexo FT-FVIIa tem como substratos principais o fator IX e o fator X, cuja clivagem resulta na formação de FIXa e FXa, respectivamente, com subseqüente formação de trombina e fibrina (Figura 2).
Deve ser ressaltado, no entanto, que quantidades mínimas de trombina são geradas a partir do complexo "protrombinase" extrínseco. Todavia, uma vez que há gênese inicial de trombina, esta enzima é capaz de ativar o fator $\mathrm{V}$ em fator Va, e o fator VIII em fator VIIIa. As duas reações, envolvendo ativação de procofatores são fundamentais para a geração do complexo "tenase" intrínseco (fator IXa/fator VIIIa), o qual converte o fator $\mathrm{X}$ em fator Xa, e do complexo "protrombinase" (fator Va/fator $\mathrm{Xa}$ ), que converte a protrombina em trombina (Figura 2). Um importante aspecto dessas reações é que o complexo fator IXa/fator VIIIa ativa o fator X com eficiência 50 vezes maior que o complexo fator VIIa/FT. O produto principal das citadas reações, a trombina (IIa), exibe atividades procoagulantes, convertendo o fibrinogênio em fibrina, promovendo ativação plaquetária e ativando o fator
XIII da coagulação, que, por sua vez, estabiliza o coágulo de fibrina.

A Figura 3 mostra, em maior detalhe, o conjunto de reações envolvidas na coagulação do sangue, com ênfase para as etapas sequienciais em que zimogênios de serinoproteases são transformados em enzimas proteolíticas. Em tal esquema, fica enfatizado o conceito de que não há distinção clara entre os sistemas intrínseco e extrínseco, que atuam de modo altamente interativo in vivo. Em condições fisiológicas, as reações esquematizadas nas Figuras 2 e 3 resultam em produção equilibrada de quantidades apropriadas de trombina e do coágulo de fibrina, em resposta adequada e proporcional à injúria vascular existente. Com efeito, no estado fisiológico não há formação e deposição de fibrina no intravascular, em decorrência das propriedades anticoagulantes do endotélio, à forma inativa das proteínas plasmáticas, envolvidas na coagulação (que circulam como zimogênios ou cofatores), e à presença de inibidores fisiológicos da coagulação (vide infra). Por outro lado, a perda do equilíbrio dinâmico das reações da coagulação têm, como conseqüência clínica, o aparecimento de distúrbios hemorrágicos ou trombóticos.

Finalmente, vale mencionar que, no que se refere ao sistema de coagulação, a utilização dos termos "intrínseco" e "extrínseco" pode ser ainda útil na interpretação de dois exames laboratoriais, utilizados

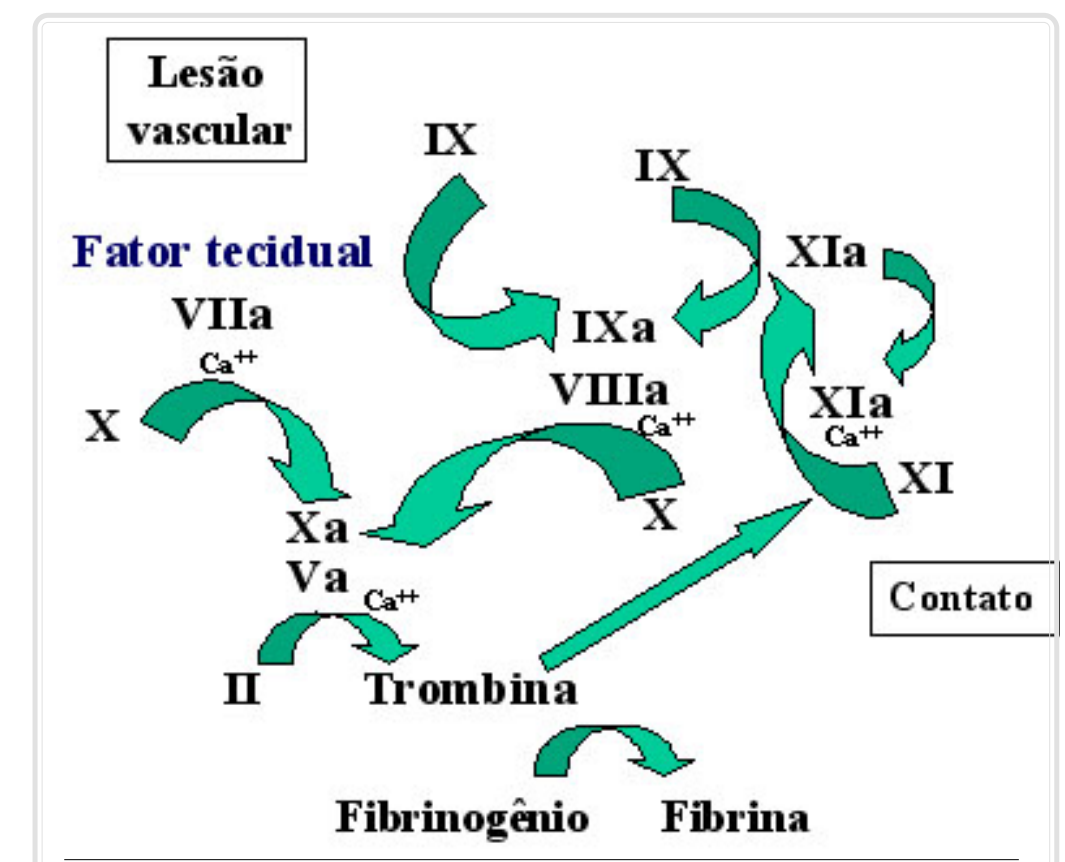

Figura 3: Visão atualizada da coagulação sangüínea. As diferentes reações ocorrem em superfícies de membrana, contendo fosfolípides (não representadas no esquema). 
na rotina da avaliação da hemostasia: o TP/INR e o TTPA, que são de particular importância no diagnóstico de anormalidades hemostáticas e na monitorização de terapêutica anticoagulante. Na execução desses testes in vitro, criam-se, no tubo de reação, as condições para ativação preferencial das vias ditas extrínseca (avaliada pelo TP) e intrínseca (avaliada pelo TTPA). À parte da utilidade mencionada, de caráter puramente didático e de interpretação laboratorial, a divisão do sistema de coagulação em duas vias é inadequada para a compreensão da sua fisiologia. De fato, os conceitos de que o fator tecidual é o principal ativador da coagulação do sangue e de que a distinção entre sistemas extrínseco e intrínseco não existe na fisiologia do sistema representam importantes mudanças conceituais, que devem ser assimiladas para entendimento correto dos eventos bioquímicos, envolvidos na ativação do sistema hemostático.

\section{MECANISMOS REGULADORES DA COA- GULAÇÃO SANGÜÍNEA}

As reações bioquímicas da coagulação do sangue devem ser estritamente reguladas, de modo a evitar ativação excessiva do sistema, formação inadequada de fibrina e oclusão vascular. De fato, a atividade das proteases operantes na ativação da coagulação é regulada por numerosas proteínas inibitórias, que atuam como anticoagulantes naturais. No presente capítulo, discutiremos as que apresentam maior relevância biológica, atuando como inibidores fisiológicos da coagulação: o TFPI ("tissue factor pathway inhibitor"), a proteína C (PC) e a proteína $\mathrm{S}$ (PS), e a antitrombina (AT) ${ }^{(9)}$.

Conforme mencionado previamente, o complexo fator VIIa/FT atua sobre dois subtratos principais: os fatores IX e X da coagulação, ativando-os. Essas reações são reguladas pelo inibidor da via do fator tecidual (TFPI), uma proteína produzida pelas células endoteliais, que apresenta três domínios do tipo "Kunitz”. O primeiro domínio liga-se ao complexo fator VIIa/FT, inibindo-o, e o segundo domínio liga-se e inibe o fator Xa. Assim, a ativação direta do fator $\mathrm{X}$ é regulada negativamente de modo rápido na presença do TFPI, que limita, desta forma, a produção de fator Xa e fator IXa (Figura 4). A ligação do fator Xa é necessária para que o TFPI exerça seu papel inibitório sobre o complexo fator VIIa/FT.

Outra importante via de anticoagulação do sangue é o sistema da PC ativada (PCa). A PC, quando ligada ao seu receptor no endotélio (EPCR, "endothelial PC receptor"), é ativada após a ligação da trombina ao receptor endotelial trombomodulina (TM) (Figura 5). A PCa inibe a coagulação, clivando e inativando os fatores Va e VIIIa, processo que é potencializado pela PS, que atua como um cofator não enzimático nas reações de inativação. A identificação do sistema da PCa implicou importante mudança conceitual no que se refere ao papel da trombina no sistema hemostático: não obstante ela tenha função procoagulante, quando gerada em excesso, sua função, na fisiologia do sistema, em que é produzida apenas em pequenas quantidades, é a de um potente anticoagulante, tendo em vista que sua ligação à TM endotelial representa o evento-chave para ativação da via inibitória da PC.

A AT (anteriormente designada AT III) é o inibidor primário da trombina e também exerce efeito inibitório sobre diversas outras enzimas da coagulação, incluindo os fatores IXa, Xa, e XIa (Figura 6). Adicionalmente, a AT acelera a dissociação do complexo fator VIIa/fator tecidual e impede sua reassociação. Assim, a AT elimina qualquer atividade enzimática procoagulante excessiva ou indesejável. A molécula de heparan sulfato, uma proteoglicana presente na membrana das células endoteliais, acelera as

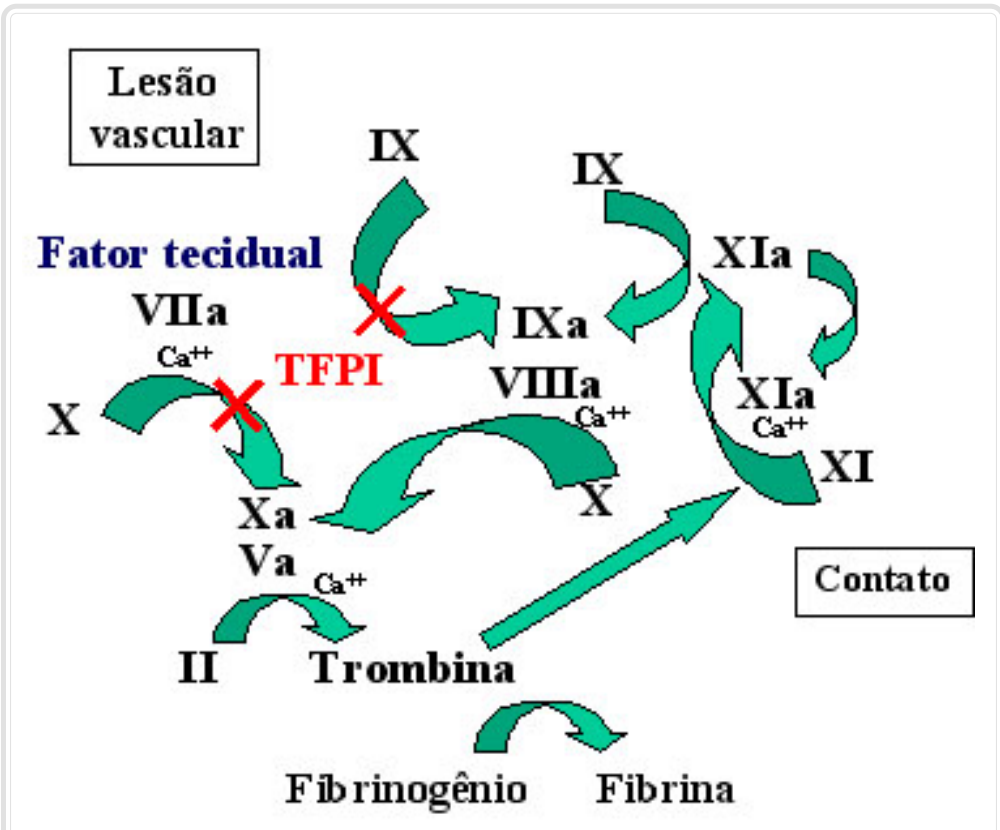

Figura 4. Inibição da via de ativação da coagulação dependente do fator tecidual pelo TFPI ("tissue factor pathway inhibitor"). O símbolo C indica os pontos de inibição do TFPI. 


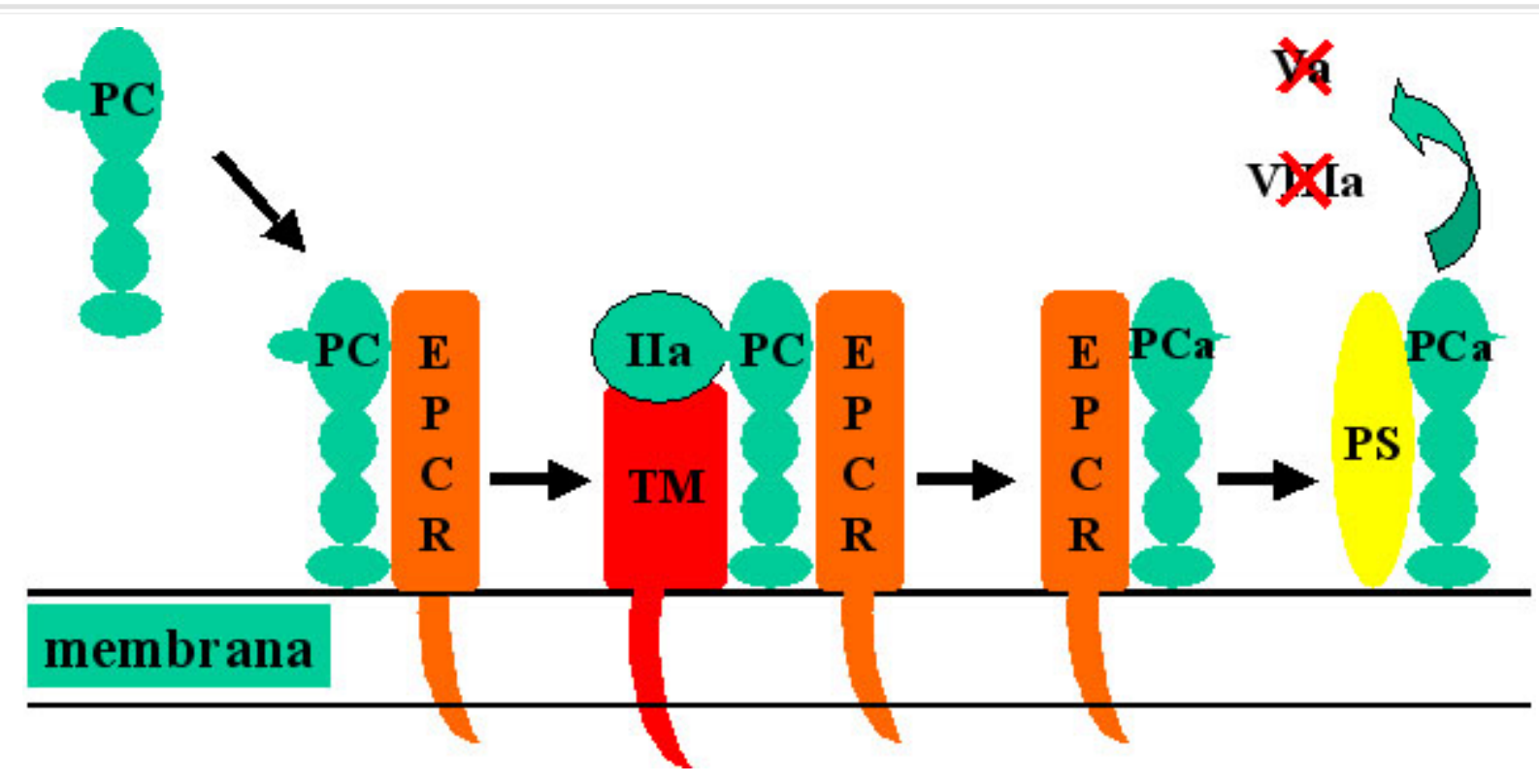

Figura 5. Sistema da proteína C ativada. A ligação da trombina (Ila) ao receptor endotelial trombomodulina (TM) modifica as propriedades da trombina, transformando-a em um potente anticoagulante, por ativar a PC, que, juntamente com seu cofator (PS), inativa os fatores VIIla e Va, suprimindo a gênese de trombina. EPCR: "endothelial PC receptor" (receptor endotelial da PC).

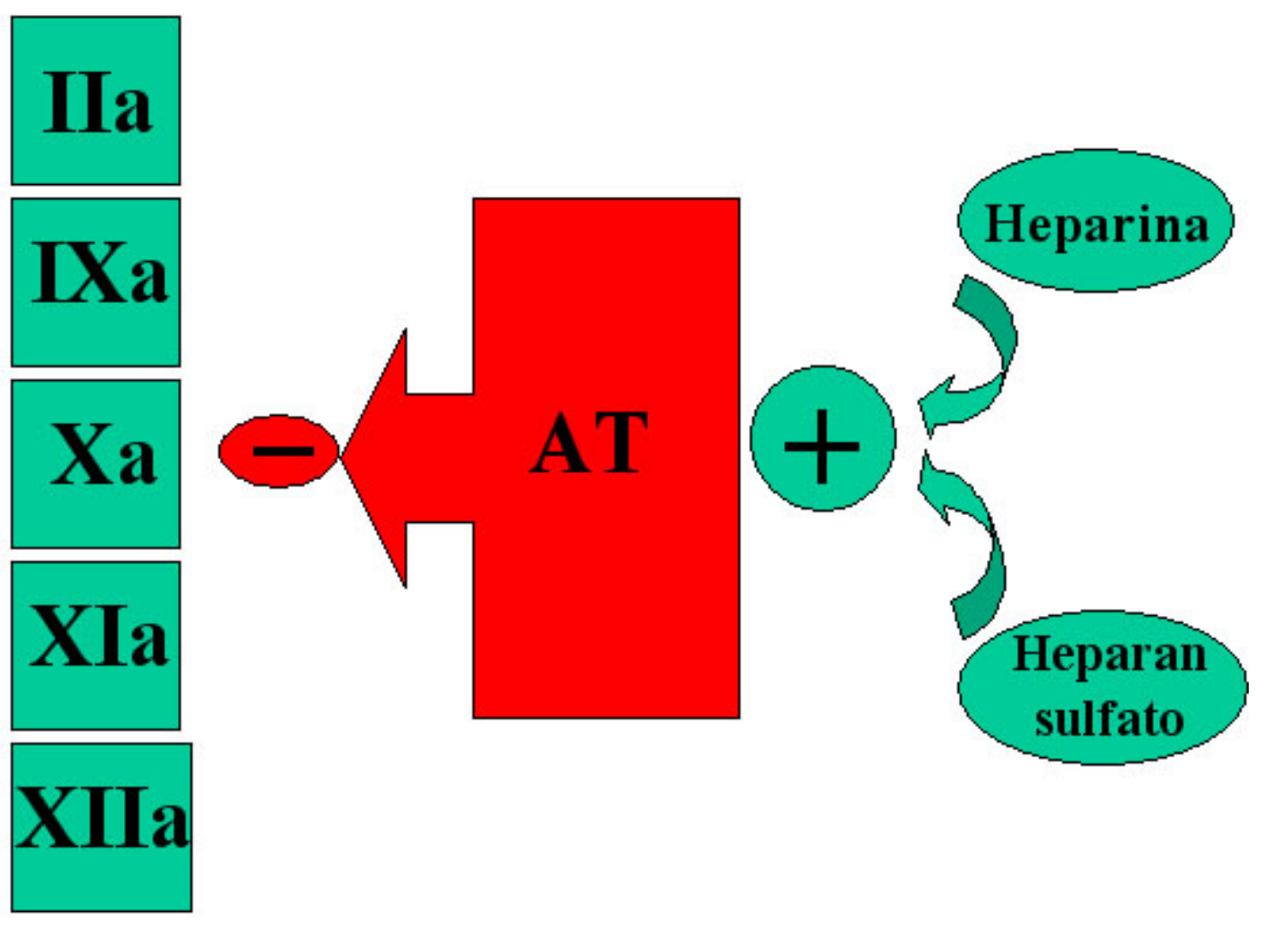

Figura 6. Efeitos anticoagulantes da antitrombina (AT). A potenciação do efeito inibitório da AT pelo heparan sulfato e heparina encontra-se também representada. 
reações catalisadas pela AT (Figura 6). A atividade inibitória da AT sobre a coagulação é também potentemente acelerada pela heparina (Figura 6), um polissacarídeo linear, estruturalmente similar ao heparan sulfato.

As diferentes vias regulatórias, citadas anteriormente, não operam isoladamente, pois há sinergismo entre o TFPI e a AT e entre o TFPI e o sistema da PC, suprimindo a gênese de trombina. Por exemplo, a AT (mas não o TFPI) inibe a ativação do fator VII, mediada pelo fator Xa, no complexo fator VII/FT. Por outro lado, o TFPI (mas não a AT) inibe o excesso de ativação do fator X pelo complexo fator VII/FT. Adicionalmente, o TFPI, em conjunção com o sistema da $\mathrm{Pca}$, inibe potentemente a gênese de trombina pelo complexo fator VII/FT.

Em condições fisiológicas (ausência de lesão vascular) há predomínio dos mecanismos anticoagulantes sobre os procoagulantes, mantendo-se, desta forma, a fluidez do sangue e preservando-se a patência vascular.

\section{SISTEMA PLASMINOGÊNIO/PLASMINA (SISTEMA FIBRINOLÍTICO)}

Fibrinólise pode ser definida como a degradação da fibrina, mediada pela plasmina. O sistema fibrinolítico ou sistema plasminogênio/plasmina é composto por diversas proteínas (proteases séricas e inibidores), que regulam a geração de plasmina, uma enzima ativa, produzida a partir de uma proenzima inativa (plasminogênio), que tem por função degradar a fibrina e ativar metaloproteinases de matriz extracelular ${ }^{(10)}$. À parte seu papel no sistema hemostático, nos últimos anos, foram descobertas numerosas funções do sistema plasminogênio/plasmina em outros processos, incluindo remodelagem da matriz extracelular, crescimento e disseminação tumoral, cicatrização e infecção, mas tais aspectos não serão aqui abordados.

As enzimas do sistema fibrinolítico são todas serinoproteases, ao passo que os inibidores da fibrinólise são membros da superfamília de proteínas designadas serpinas (inibidores de proteases séricas). São conhecidos dois ativadores fisiológicos do plasminogênio: o ativador do plasminogênio do tipo tecidual (t-PA, "tissue-type plasminogen activator") e o ativador do plasminogênio do tipo uroquinase (u-PA, "urokinase-type plasminogen activator") (Figura 7). Os dois ativadores têm alta especificidade de ligação com seu substrato (plasminogênio) e promovem hidrólise de uma única ponte peptídica $\left(\mathrm{Arg}^{560}-\mathrm{Val}^{561}\right)$, que resulta na formação de uma serinoprotease ativa, a plasmina. Embora a plasmina degrade não somente a fibrina, mas, também, o fibrinogênio, fator $\mathrm{V}$ e fator VIII, em condições fisiológicas, a fibrinólise ocorre como processo que é altamente específico para a fibrina, portanto de ativação localizada e restrita, e não sistêmica, cumprindo, assim, sua função de remover o excesso de fibrina do intravascular de modo equilibrado. Esta especificidade dependente de fibrina é resultado de interações moleculares específicas entre os ativadores do plasminogênio, o plasminogênio, a fibrina, e os inibidores da fibrinólise. Por exemplo, o t-PA exibe baixa afinidade pelo plasminogênio na ausência de fibrina $\left(\mathrm{K}_{\mathrm{M}}=65 \mu \mathrm{M}\right)$, afinidade que é muito aumentada na presença de fibrina $\left(\mathrm{K}_{\mathrm{M}}=0,15-1,5 \mu \mathrm{M}\right)$, o que ocorre porque a fibrina representa uma superfície ideal para ligação do t-PA ao plasminogênio, e em tal reação, o plasminogênio liga-se à fibrina via resíduos de aminoácido lisina ("lysine-binding sites"). Em contraste com esses mecanismos fisiológicos, ativação mais extensa do sistema fibrinolítico ocorre quando da infusão de agentes trombolíticos do tipo estreptoquinase e uroquinase, que não são específicos para a presença de fibrina.

A inibição do sistema fibrinolítico ocorre em nível dos ativadores do plasminogênio mediante ação de inibidores específicos (PAIs, "plasminogen activator inhibitors"), cujo principal representante é o PAI-1, e diretamente sobre a plasmina, função inibitória exercida pela $\mathrm{a}_{2}$-antiplasmina (Figura 7).

Recentemente, um novo componente do sistema fibrinolítico foi identificado e designado TAFI ("thrombin-activatable fibrinolysis inhibitor", inibidor da fibrinólise, ativado pela trombina, também denominado carboxipeptidase B plasmática, procarboxipeptidase $\mathrm{U}$ ou procarboxipeptidase $\mathrm{R})^{(11)}$. O TAFI é um zimogênio plasmático que ocupa importante papel na hemostasia, funcionando como um potente inibidor da fibrinólise. O TAFI é ativado pela trombina, tripsina e plasmina, e, na sua forma ativada, é capaz de inibir a fibrinólise por remover resíduos de lisina da molécula de fibrina durante o processo de lise do coágulo, suprimindo,assim, as propriedades de cofator da fibrina parcialmete degradada na ativação do plasminogênio. Curiosamente, a principal via de ativação do TAFI é dependente da ligação do fator IIa (trombina) à trombomodulina (complexo que tem também a função de ativar o sistema da proteína C). Dessa forma, a molécula do TAFI representa um ponto de conexão entre os sistema de coagulação e fibrinolítico, fato ilustrado na Figura 8. 


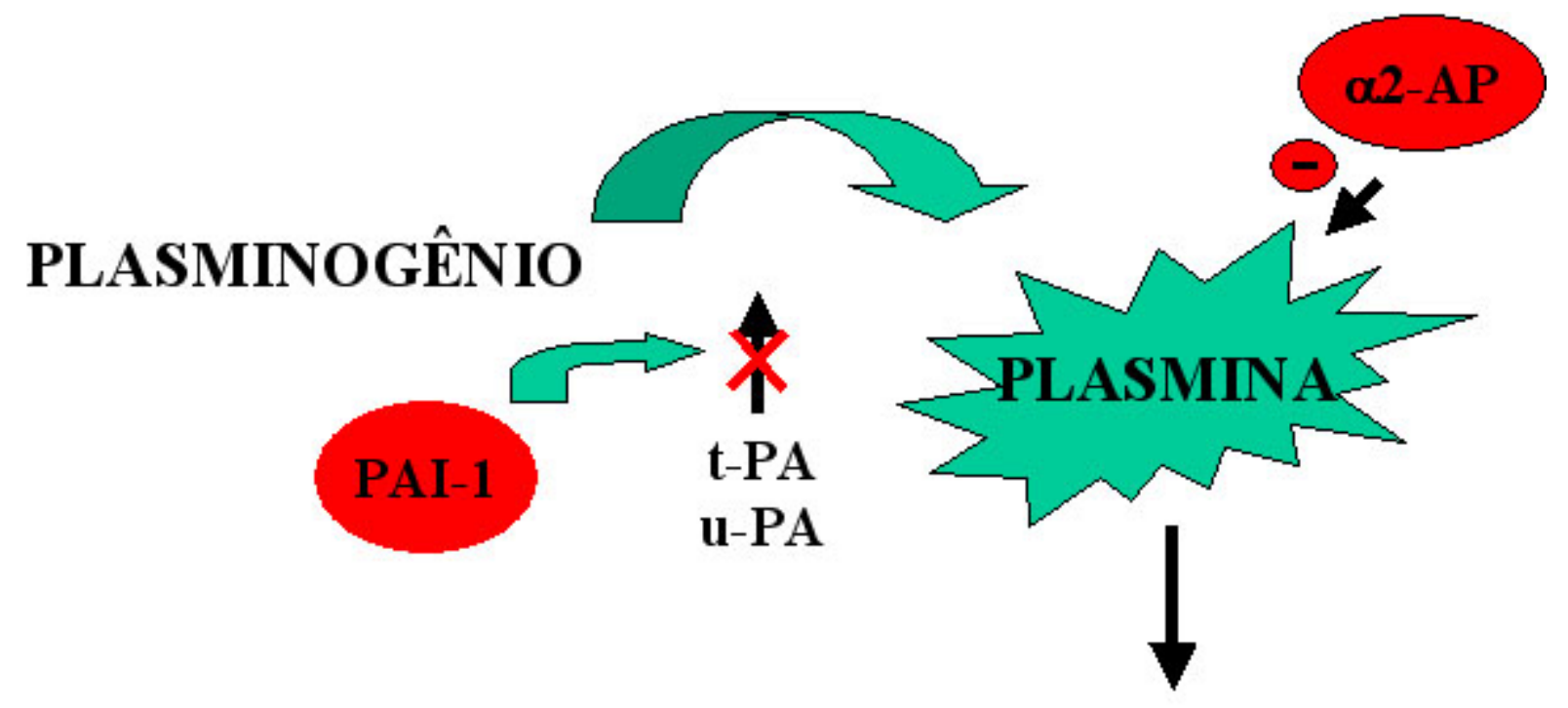

Fibrina $\rightarrow$ PDF

Figura 7: Representação esquemática do sistema fibrinolítico. PDF: produtos de degradação de fibrina. Outras siglas: vide texto.

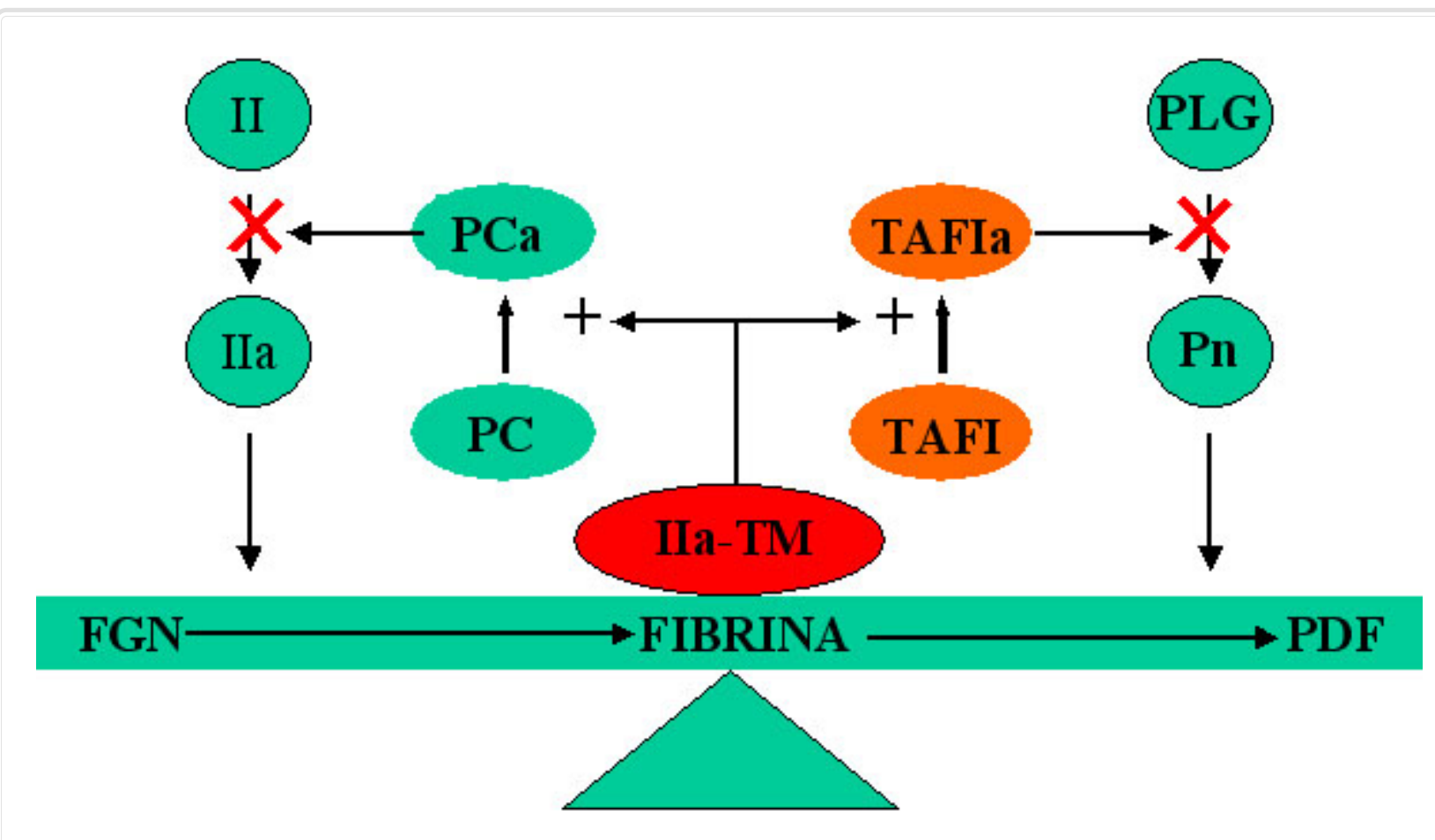

Figura 8: TAFI: ponto de conexão entre o sistema de coagulação e da fibrinólise, intermediado pelo complexo trombina/ trombomodulina. Esquema adaptado da referência 11. PLG: plasminogênio, Pn: plasmina, TM: trombomodulina, FGN: fibrinogênio, PDF: produtos de degradação de fibrina. 
FRANCO RF. Overview of coagulation, anticoagulation and fibrinolysis. Medicina, Ribeirão Preto, 34: 229-237, july/dec. 2001.

ABSTRACT: The present article revises different aspects of the coagulant, anticoagulant and fibrinolytic systems, which are relevant for a better understanding of aetiopathogenetic mechanisms operating in bleeding and thrombotic disorders.

UNITERMS: Coagulation. Anticoagulation. Fibrinolysis.

\section{REFERÊNCIAS BIBLIOGRÁFICAS}

1 - JENNY NS \& MANN KG. Coagulation cascade: an overview. In: LOSCALZO J \& SCHAFER Al, eds. Thrombosis and hemorrhage, $2^{\text {nd }}$ ed, Williams \& Wilkins, Baltimore, p. 3-27, 1998.

2 - COLMAN RW; CLOWES AW; GEORGE JN; HIRSH J \& MARDER VJ. Overview of hemostasis. In: COLMAN RW; HIRSH J; MARDER VJ; CLOWES AW \& GEORGE JN, eds. Hemostasis and thrombosis. Basic principles and clinical practice, $4^{\text {th }}$ ed, Lippincott; Williams \& Wilkins, Philadelphia, p. 316, 2001.

3 - MACFARLANE RG. An enzyme cascade in the blood clotting mechanism, and its function as a biochemical amplifier. Nature 202: 498-499, 1964.

4 - DAVIE EW \& RATNOFF OD. Waterfall sequence for intrinsic blood clotting. Science 145: 1310-1312, 1964.

5 - DRAKE TA; MORRISSEY JH \& EDGINGTON TS. Selective cellular expression of tissue factor in human tissues: implications for disorders of hemostasis and thrombosis. Am $\boldsymbol{J}$ Pathol 134: 1087-1097, 1989.

6 - WILCOX JN; SMITH KM; SCHWARTZ SM; SCHWARTZ SM \& GORDON D. Localization of tissue factor in the normal vessel wall and in the atherosclerotic plaque. Proc Natl Acad Sci USA 86: 2839-2843, 1989.
7 - VAN DEVENTER SJH; BULLER HR; TEN CATE JW; AARDEN LA; HACK CE \& STURK A. Experimental endotoxemia in humans: Analysis of cytokine release and coagulation, fibrinolytic and complement pathways. Blood 76: 2520-2527, 1990.

8 - FRANCO RF; DE JONGE E; DEKKERS PEP; TIMMERMAN JJ; SPEK CA; VAN DEVENTER SJH; VAN DEURSEN P; VAN KERKHOFF L; VAN GEMEN B; TEM CATE H; VAN DER POLL \& REITSMA PH. The in vivo kinetics of tissue factor mRNA expression during human endotoxemia: relationship with activation of coagulation. Blood 96: 554-559, 2000.

9 - COLMAN RW; HIRSH J; MARDER VJ \& CLOWES AW. Overview of coagulation, fibrinolysis, and their regulation. In: COLMAN RW; HIRSH J; MARDER VJ; CLOWES AW \& GEORGE $\mathrm{JN}$, eds. Hemostasis and thrombosis. Basic principles and clinical practice, $4^{\text {th }}$ ed, Lippincott; Williams \& Wilkins, Philadelphia, p. 17-20, 2001.

10 - COLLEN D. The plasminogen (fibrinolytic) system. Thromb Haemost 82: 259-270, 1999.

11 - BAJZAR L. Thrombin activatable fibrinolysis inhibitor and na antifibrinolytic pathway. Arterioscler Thromb Vasc Biol 20: 2511-2518, 2000.

Recebido para publicação em 28/06/2001

Aprovado para publicação em 24/08/2001 